\title{
LANE CHANGING CHARACTERISTICS FOR DIFFERENT TYPES OF ROADS IN NAJAF
}

\author{
HAMID A. AL-JAMEEL ${ }^{1,}{ }^{*}$, and ALI JIHAD KADHAM ${ }^{* *}$ \\ *Faculty of Engineering, University of Kufa, , Kurdistan Region-Iraq \\ ${ }^{* *}$ Faculty of Engineering, University of Al-Mustansiriayah,-Iraq
}

(Accepted for Publication: December 8, 2020)

\begin{abstract}
Investigating a driver behavior under different traffic conditions is the main point to develop a microscopic traffic model such as the Frequency of Lane Changing (FLC) and Lane Utilization (LU). The LC model is the corner stone for developing each traffic software; especially traffic simulation models. The main aim of this study is to investigate the FLC and LU under different traffic conditions such as urban and rural roads. Furthermore, the FLC for each type of road two-or three-lane sections has been investigated. Field data have mainly been collected from urban arterial roads; whereas other published data have been used for this study. High FLC has been observed in Iraqi roads comparing with other countries. This behavior could be attributed to the aggressive behavior and the absence of pavement parking.
\end{abstract}

KEYWORD: Lane Changing, Lane utilization, Urban roads, Driver behavior

\section{INTRODUCTION}

$\mathbf{T}$ Traffic congestion problem has been widely increasing through the world. Iraq is one of the countries which suffer from high problems in traffic operation, in order to solve such problem, a study of the traffic characteristics should be implemented. Several methods have been adopted by researchers to improve flow. These methods such as Highway Capacity Manual (HCM) and optimization are based on mathematical equations which mainly depend on theoretical or empirical background. It has been found that knowing driver behavior such as Lane utilization (LU) and Lane Changing (LC) which is the key to use these simulation models such as VISSIM, AIMSUN and Gipps models (Hidas, 2005).

The LU represents how the vehicles are distributed among lanes. The importance of studying the LU comes from the importance of its use in calibrating the parameters of microsimulation models (Shirke et al., 2017). The LU depends on traffic regulation, traffic configuration, speed and traffic volume, number of and location of access points, rules of overtaking, discipline of lanes, the origin-destination patterns of drivers, development environment and different drivers' habits in each country (HCM, 2010, Pompigna and Rupi, 2017). The behavior of drivers on the road varies from one country to another where they are influenced by the common cultures in the country (Nordfjærn and Rundmo, 2009). Pavement surface deformities also affect the behavior of LU as well as the type and speed of the vehicle (Aydin and Topal, 2017).

The LC model is considered as the second grade after the model of the car following in its importance in building the microsimulation model, and also has an impact on the evaluation of macroscopic characteristics due to the impact of interference on traffic characteristics (Moridpour et al., 2010a, and Aydın and Topal, 
2017). The LC is the process of changing the vehicle's position from a lane to another lane for reasons related to the driver's behavior in response to a specific goal or for other reasons forced the driver to change the lane. The LC is more complicated because the decision to change lanes depends on several targets, and sometimes some of them may conflict with the others (Al-Jameel, 2012). The LC behavior can be affected by several different factors such as driver characteristics, pavement surface characteristics and traffic flow condition, deformation in the surface of the pavement have an effect on the process of changing the lane and vary depending on the driver's age and gender and his/her conditions, and the speed of his/her vehicle (Aydin et al., 2014, and Aydın and Topal, 2017).

In Iraq, very limited studies have been achieved to investigated the LU and LC. Al-Jameel (2017) and Al-Jameel and Kadhim (2018) conducted specific studies for normal sections in rural area. These sections included two and three lane sections only. Therefore, this study has focused on studying the behavior of LU and LC in urban roads such as Al-Kufa-Najaf road.

\section{LANE UTILIZATION}

Previous studies had been conducted in different countries that showing how vehicles are distributing on the road according to the rules of traffic for each country and show the behavior of the driver when using the lane according to different circumstances of the road from a low to high traffic or congestion level. One of the important comparisons in this regard is presented by Pompigna and Rupi (2017), where they compared the differences in LU between Italy and other European countries (Netherlands, Germany and UK) and non-European countries (Turkey, USA, Japan and Canada).

The main point here to describe is the numbering of lanes for the roads. The first lane represents the slowest lane which is the closet lane from the shoulder. Whereas, the highest lane number is the highest speed lane which is the closest to the median. The numbering of lanes starts from the right one.

It has been shown that there are many common features between different countries, for example, the use of the third lane increases as the traffic flow increases. This could be attributed to the lack of a suitable opportunity to increase speed in the other lanes due to high flow. Accordingly, the high percentage of traffic moves from the first and second lanes toward the third lane.

Figure 1 indicates the comparison that conducted by Pompigna and Rupi based on previous studies in different countries such as the United States, Canada, Germany and Japan. As a summary of this comparison, Pompigna and Rupi (2017) proposed three groups of similar countries in terms of the distribution of vehicles on the available lanes: the first group consists of Canada and the United States, with the distribution of the lane is not overly uneven. The second group consists of Italy, Turkey, UK, and Germany, with heterogeneity becomes more pronounced, especially in the first lane. The third group consists of Netherlands, and Japan, with all the lanes increasingly showing greater heterogeneity. While Figure 2 shows a comparison between LU in the UK and Germany for two lanes and it is clear that LU in the two countries is similar (Yousif, 1993).

Mainly, Figure 1 demonstrates that the ratio of vehicles using the first lane under low flow is high comparing with other lanes. Whereas, the LU of the third lane is so low under low flow because it may be used just for passing slowing vehicles. Then, as flow increase from moderate to high, the highest ratio of vehicles (high LU\%) is concentrated at the third lane for the same reason mentioned above. On the other hand, the behavior of LU for UK and Germany drivers' behavior as indicated in Figure 2 is approximately the same as mentioned in Figure 1 . 

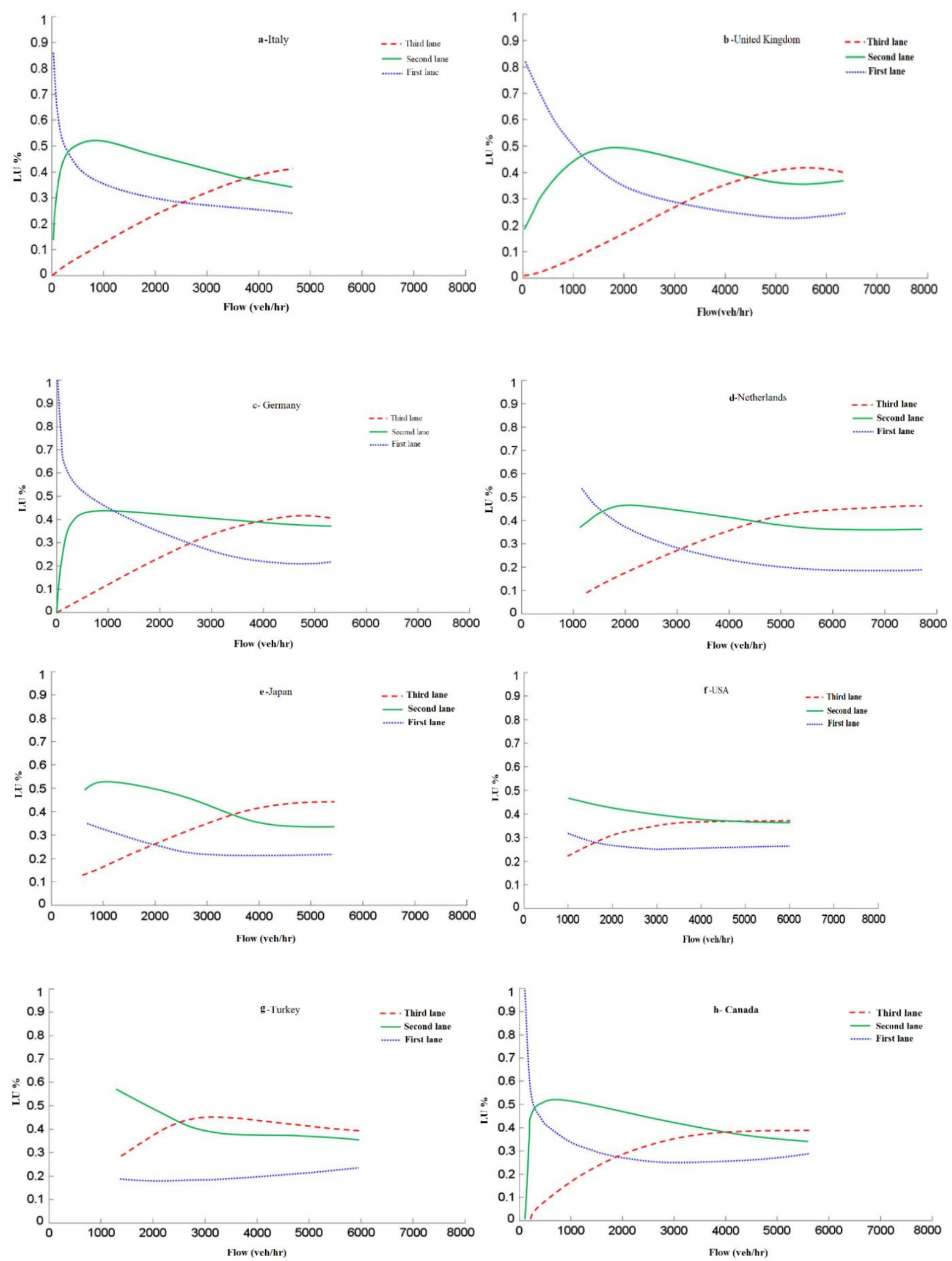

Fig. (1): Comparison of lane utilization (LU) in different countries, European countries (a-Italy, b-United Kingdom, c-Germany, and d-Netherlands), and non-European countries (e-Japan, f-United States, g-Turkey, and h-Canada) (Pompigna and Rupi, 2017).

hamid.aljameel@uokufa.edu.iq; alijkr1993@gmail.com 


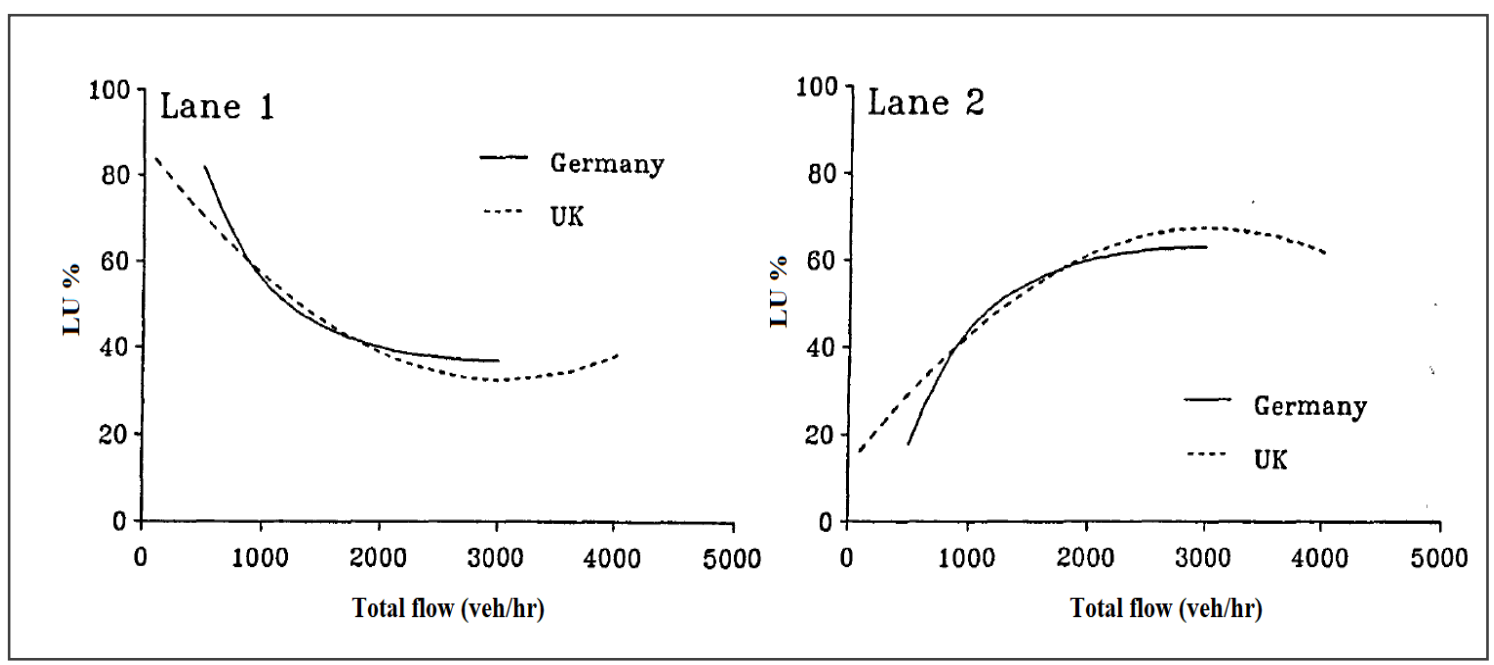

Fig. (2): Comparison of lane utilization (LU) for two lanes between UK and Germany (Yousif, 1993).

\section{LANE CHANGING MODELS (LC)}

The process of LC is linked to the characteristics of both the driver and the vehicle, and in order to understand this process so there is a need to study these characteristics. Several researchers represented the behavior of changing the lane, either through simulation, mathematical analysis or experimental analysis as mentioned by $\mathrm{Xu}$ et al. (2012) which summarizes the methods and models of analysis of the behavior of LC. The frequency of lane change (FLC) has an impact on safety in the roads. The more frequent of lane changings leads to more traffic accidents (Do et al., 2017). Figure 3 demonstrates the general structure of LC (Toledo, 2007). As the driver of following vehicle trying to change the lane into another direction (either to the right or left) according to the available gap or if the appropriate gap is not available, the vehicle will remain in the current lane.

The LC model was classified as a mandatory lane change (MLC) or a discretionary lane change (DLC) (Ghaffari et al., 2015). MLC, it occurs when the driver is obliged to leave the lane or change the lane to reach his/her destination, for example, to use an off-ramp or because of the presence of a vehicle speeding behind the vehicle or the existence of roadwork (Nassrullah, 2016).

DLC, this is done to improve driving conditions and make them more comfortable and changing the lane is not required or unnecessary in this case (Ramanujam, 2007), for example, change the lane to achieve a higher speed and to exceed the slow leading vehicle or to exceed the following trucks or to stay away from the merger sections in traffic.

The classification of the mandatory lane changes into three types namely free, forced, and cooperative (Hidas, 2005), and for more details see for example Choudhury et al. (2009). Moreover, information about the lane change in terms of types and classifications model see Rahman et al. (2013). 


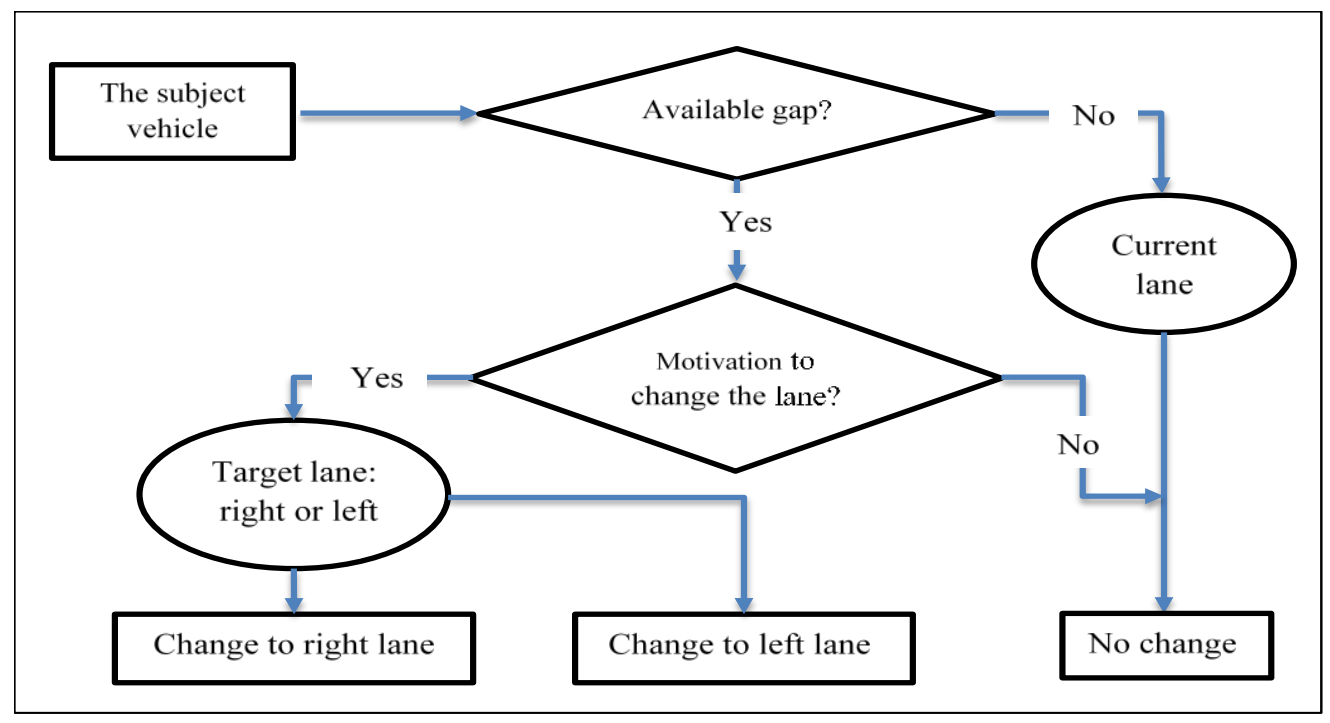

Fi. (3). The general structure of lane change (Toledo, 2007).

\section{IRAQI BEHAVIOR FROM PREVIOUS STUDIES}

Few Iraqi studies have focused on studying the LC and LU such as Al-Jameel (2017) and Al-Jameel and Kadhim (2018). The both studies were conducted to study both LU and LC for two and three lane normal sections in rural area. Figure 4 indicates that the LU behavior in Iraq for three lane section is different among other countries. Whereas, the behavior of LU for two lane section is indicated in Figure 5.

Al-Jameel (2017) has found that the LU behavior in Iraq is different in comparison with behavior in the UK because Iraqi drivers prefer to be in the fast lane (lane 3) even under low flow as in Figure 4. This figure demonstrates that the most vehicles concentrate on the second lane under different level of flow.

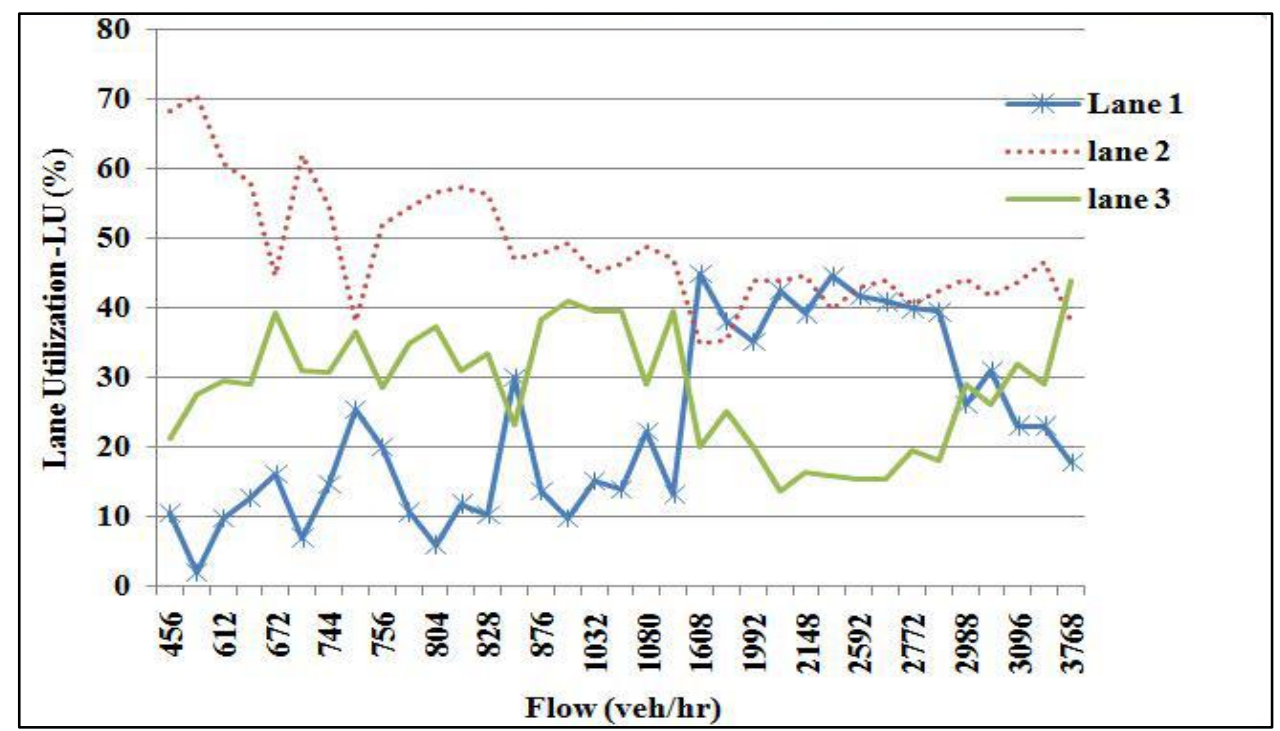

Fig. (4): LU for three lane section in Iraqi roads (Al-Jameel, 2017).

hamid.aljameel@uokufa.edu.iq; alijkr1993@gmail.com 
Al-Jameel and Kadhim (2018) conducted field observations for two and three lane sections for both the LU and LC characteristics. They found that the LU behavior is different from other countries due to the concentration of vehicles in the fast lane (third lane) and second lane even under the low flow which could be attributed to the bad surface conditions of first lane (slow lane). Therefore, Figure 5 indicates that the high ratio of LU for two-lane section in Iraq is on the second lane under different level of flow. On the other hand, the authors found that the number of LC is higher than other countries because of several causes such as right passing and absence of pavement markings. Whereas the author found that the LC behavior is similar to the UK, however; the number of LC is much higher than the observed one in the UK.

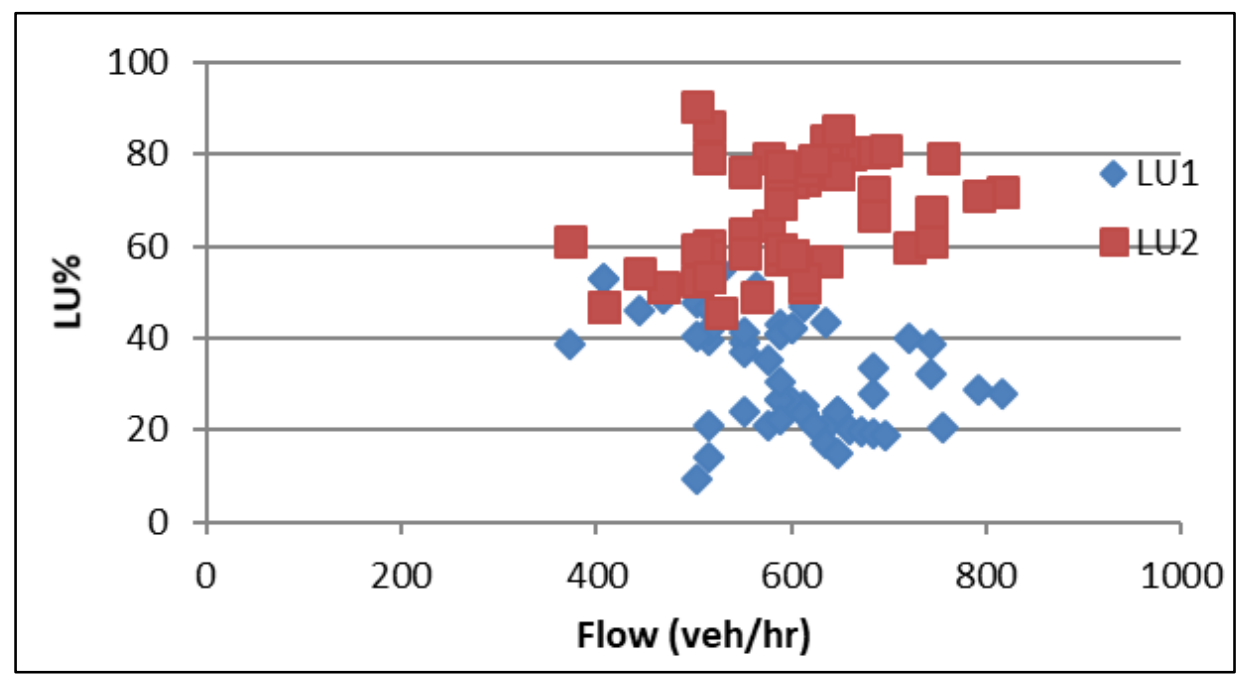

Fig. (5): LU of two lane section in Iraq(Al-Jameel and Kadhim, 2018).

\section{DESCRIPTION OF SITES}

A section of the Najaf-Kufa road is an arterial road connecting Najaf and Kufa as shown in
Figure 6. The road to Kufa contains three corridors for both directions. Also in the studied section is a side passageway. Table 6 shows the characteristics of the site.

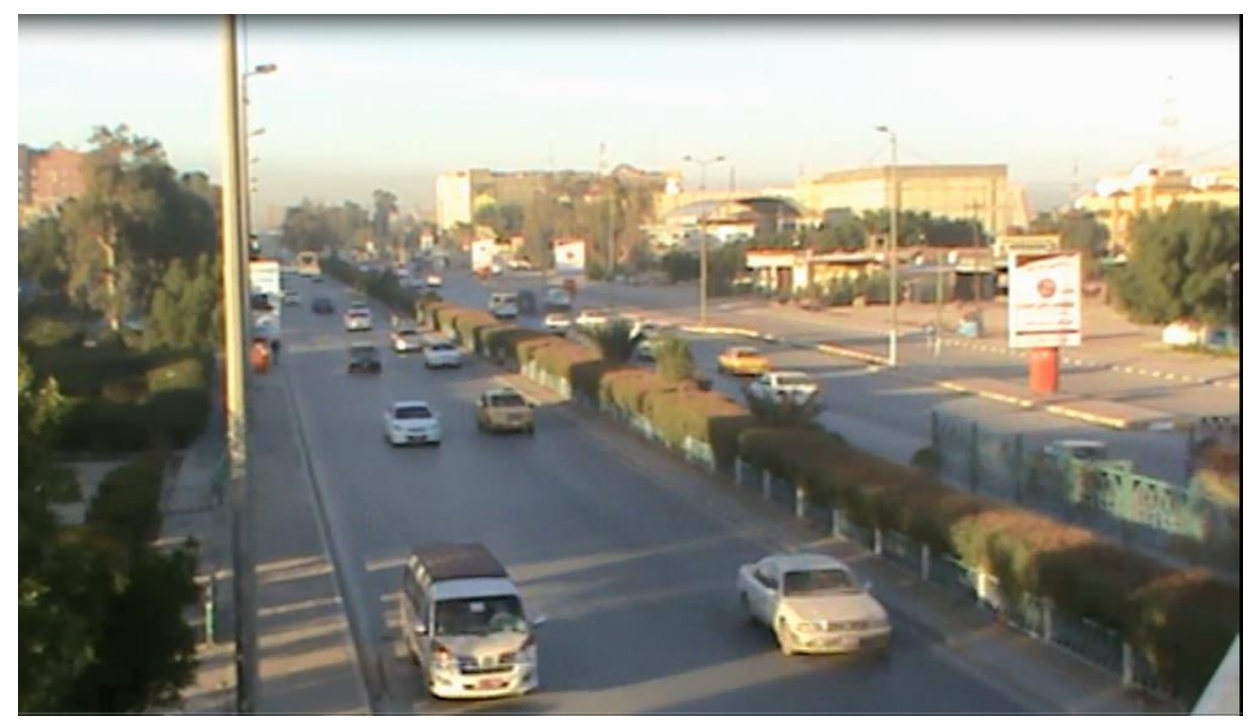

Fig. (6): Section in Kufa-Najaf road.

hamid.aljameel@uokufa.edu.iq; alijkr1993@gmail.com

${ }^{1}$ Corresponding author: Faculty of Engineering, University of Kufa, Najaf, Iraq 
Table (1): characteristics of the site.

\begin{tabular}{cc}
\hline Characteristics & The value or limits \\
\hline Lane width & $3.6 \mathrm{~m}$ \\
\hline Speed limit & 60 to $80 \mathrm{~km} / \mathrm{hr}$. \\
\hline Surface condition & absence of pavement marking \\
\hline
\end{tabular}

\section{DATA COLLECTION}

Different methods of data collection were used as on street parking was noticed by videos and the vantage points which have been used for data collection are the footbridges existing along this road. At present, several problems face each one collecting data from Iraqi traffic facilities such as absence of specialist traffic camera, loop detectors and other ITS means. So, the observer should provide his/her own means in order to collect data from urban or rural sites. Figure 7 shows the site details (i.e. lane distribution); the way to calculate the visibility distance of the camera on the site, and the method of point the gun speed. After surveying all sites, it was possible to monitor the videos and extract data from them. A video player and TV screen have been used to extract different types of data such as the number of vehicles (flow) in each lane; class of each vehicle; headway and number of LC. A screen of TV has been divided in two lines with the actual section in the video.

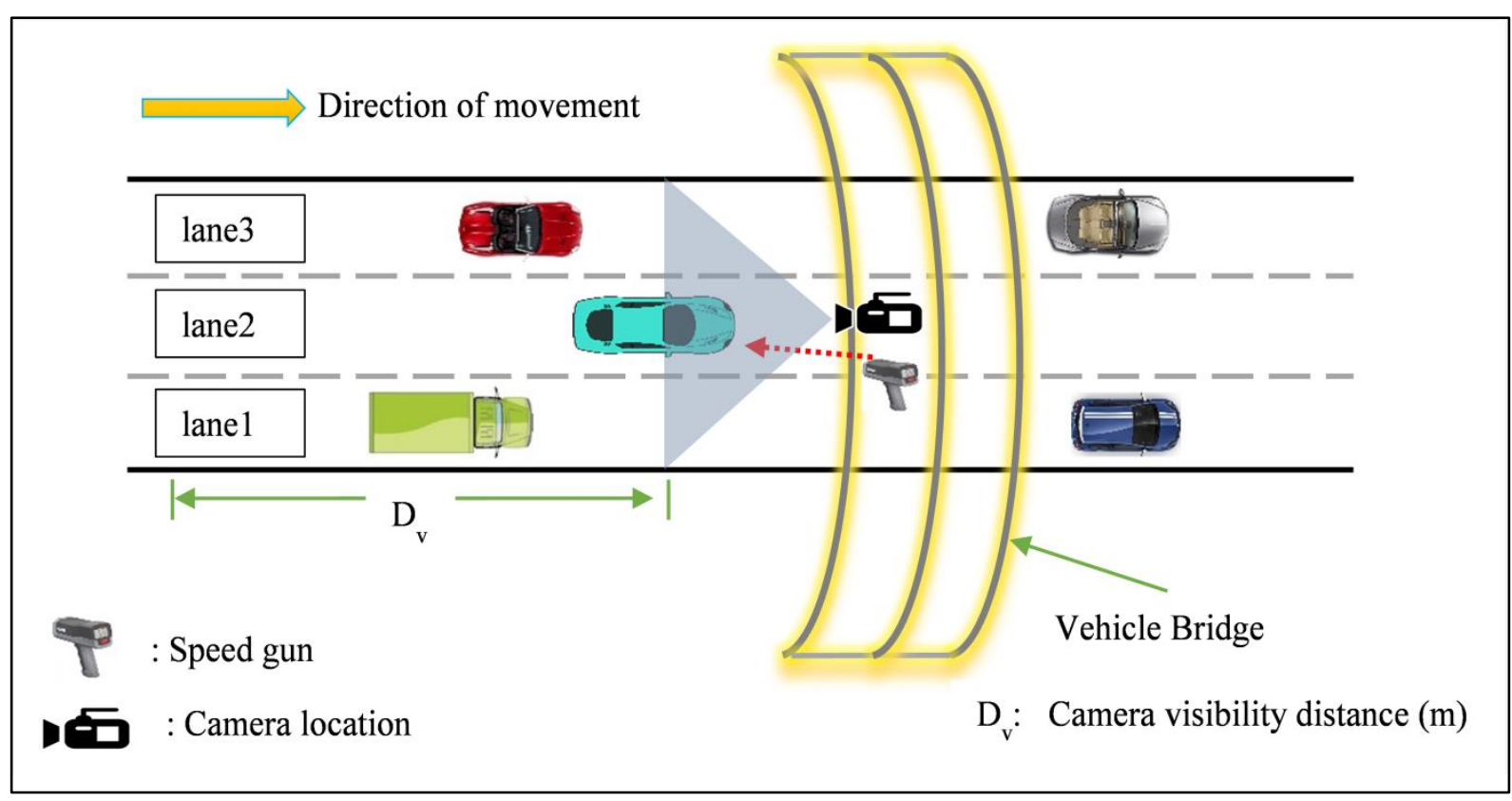

Fig. (7): Detail of site with the camera and the speed gun to measure the desired speed.

Flow has been collected by extracting flow each 15minutes as indicated in Tables 2 and 3. The point of collecting data has been investigating the flow for each lane in each direction. The point of flow was calculated for 3 lanes to Kufa and 3 lanes to Najaf. Furthermore, it was found that the percentage of minibus was so high as indicated in Table 4. It was noticed that the absence of pavement of pavement markings as indicated in Figure 6. 
Table (2): Flow rate (veh/hr) in each lane, from Kufa to Al-Najaf.

\begin{tabular}{|c|c|c|c|c|}
\hline Time (AM) & $\begin{array}{c}\text { Flow } \\
\text { lane1(veh/hr) }\end{array}$ & $\begin{array}{c}\text { Flow } \\
\text { lane2(veh/hr) }\end{array}$ & $\begin{array}{c}\text { Flow } \\
\text { lane3(veh/hr) }\end{array}$ & Total flow(veh/hr) \\
\hline $07: 30-07: 45$ & 1792 & 1632 & 1856 & 5280 \\
\hline $07: 45-08: 00$ & 1616 & 1520 & 1744 & 4880 \\
\hline $08: 00-08: 15$ & 1680 & 1552 & 1376 & 4608 \\
\hline $08: 15-08: 30$ & 1568 & 1696 & 1744 & 5008 \\
\hline $08: 30-08: 45$ & 1776 & 1760 & 1584 & 5120 \\
\hline $08: 45-09: 00$ & 1600 & 1568 & 1728 & 4896 \\
\hline 09:00 - 09: 15 & 1760 & 1584 & 2240 & 5584 \\
\hline $09: 15-09: 30$ & 1264 & 1424 & 2128 & 4816 \\
\hline $09: 30-09: 45$ & 1360 & 1216 & 2016 & 4592 \\
\hline $09: 45-10: 00$ & 848 & 992 & 1648 & 3488 \\
\hline $10: 00-10: 15$ & 672 & 624 & 1280 & 2576 \\
\hline $10: 15-10: 30$ & 576 & 656 & 1232 & 2464 \\
\hline $10: 30-10: 45$ & 704 & 656 & 1472 & 2832 \\
\hline $10: 45-11: 00$ & 784 & 880 & 1600 & 3264 \\
\hline $11: 00-11: 15$ & 912 & 768 & 1616 & 3296 \\
\hline $11: 15-11: 30$ & 768 & 864 & 1712 & 3344 \\
\hline $11: 30-11: 45$ & 800 & 944 & 1760 & 3504 \\
\hline
\end{tabular}

Table (3): Flow rate (veh/hr) on each lane, from Al-Najaf to Kufa

\begin{tabular}{|c|c|c|c|c|}
\hline Time (AM) & $\begin{array}{l}\text { Flow } \\
\text { lane1(veh/hr) }\end{array}$ & $\begin{array}{c}\text { Flow } \\
\text { lane2(veh/hr) }\end{array}$ & $\begin{array}{l}\text { Flow lane } \\
\text { 3(veh/hr) }\end{array}$ & $\begin{array}{c}\text { Total } \\
\text { flow(veh/hr) }\end{array}$ \\
\hline $07: 30-07: 45$ & 1072 & 1024 & 576 & 2672 \\
\hline $07: 45-08: 00$ & 1264 & 976 & 528 & 2768 \\
\hline $08: 00-08: 15$ & 1552 & 1152 & 560 & 3264 \\
\hline $08: 15-08: 30$ & 1584 & 1264 & 512 & 3360 \\
\hline $08: 30-08: 45$ & 1456 & 1552 & 656 & 3664 \\
\hline $08: 45-09: 00$ & 1696 & 1856 & 688 & 4240 \\
\hline $09: 00-09: 15$ & 1584 & 1744 & 672 & 4000 \\
\hline $09: 15-09: 30$ & 1760 & 1888 & 736 & 4384 \\
\hline $09: 30-09: 45$ & 1824 & 1984 & 752 & 4560 \\
\hline $09: 45-10: 00$ & 1664 & 2064 & 960 & 4688 \\
\hline $10: 00-10: 15$ & 1328 & 1584 & 560 & 3472 \\
\hline $10: 15-10: 30$ & 1440 & 1712 & 512 & 3664 \\
\hline $10: 30-10: 45$ & 1568 & 1696 & 464 & 3728 \\
\hline $10: 45-11: 00$ & 1568 & 1904 & 416 & 3888 \\
\hline $11: 00-11: 15$ & 1760 & 1840 & 512 & 4112 \\
\hline $11: 15-11: 30$ & 1824 & 2016 & 544 & 4384 \\
\hline
\end{tabular}

hamid.aljameel@uokufa.edu.iq; alijkr1993@gmail.com 


\begin{tabular}{lllll}
\hline $11: 30-11: 45$ & 1856 & 1232 & 368 & 3456 \\
\hline $11: 45-12: 00$ & 1440 & 1408 & 768 & 3616 \\
\hline $12: 00-12: 15$ & 1456 & 1392 & 560 & 3408 \\
\hline $12: 15-12: 30$ & 2368 & 1328 & 320 & 4016 \\
\hline
\end{tabular}

Table (4): Percentage of minibus with corresponding flow for a selcted period of survey.

\begin{tabular}{ccccccccccc}
\hline Flow (veh/hr) & $\mathbf{3 6 3 6}$ & $\mathbf{3 5 7 6}$ & $\mathbf{3 6 4 8}$ & $\mathbf{3 7 4 4}$ & $\mathbf{3 7 2 0}$ & $\mathbf{3 9 3 6}$ & $\mathbf{3 6 8 4}$ & $\mathbf{3 3 9 6}$ & $\mathbf{2 4 0 0}$ & $\mathbf{2 5 4 4}$ \\
\hline Minibus(\%) & 19.80 & 16.77 & 23.36 & 20.83 & 22.90 & 21.04 & 25.08 & 21.90 & 42.00 & 43.39 \\
\hline
\end{tabular}

\section{DATA ANALYSIS}

During the data analysis process, there is a task of classifying vehicles which leads to the consumption of time. Therefore, the vehicles were classified into two groups: cars and Heavy Goods Vehicles (HGVs). HGVs are defined as vehicles with more than four tiers touching the pavement (HCM, 2000) and based on this definition, vehicles were classified. The percentage of minibus is so high as indicated in Table 4.

Referring to the data collection stage, the analysis of these data indicated that the flow of vehicles towards Al-Najaf is the highest at the point of observation as indicated in Table 1 and 2. Moreover, the PHF is 0.94 and 0.98 , for Kufa and Najaf, respectively. This high value shows clearly that the survey was done at the suitable time of survey to get heavy flow.

Table 1 indicated that maximum flow (peak hour) is about $5584 \mathrm{veh} / \mathrm{hr}$. Then, a sudden bottleneck has happened due to exceeding the capacity of this road. This leads to long queue as indicated in Figure 7. Figure 8 illustrates the variation of flow in the direction toward Kufa city. The figure represents the maximum flow in this direction is up to $4688 \mathrm{veh} / \mathrm{hr}$.

Figure 5 demonstrates how the vehicles are distributed among different lanes. The first lane carries the highest percentage of vehicles whereas; the third lane is the lowest one along different levels of flow. The second lane is still the second in terms of carrying traffic for the range of flow from $2000 \mathrm{veh} / \mathrm{hr}$ up to 2600 $\mathrm{veh} / \mathrm{hr}$. Then, the second lane represents the highest with traffic stream till $3000 \mathrm{veh} / \mathrm{hr}$ and at the highest flow is still the highest lane which carries the high percentages of traffic as in Figure 8. The interpretation of such behavior could be attributed to the fact that most vehicles using such road are minibus and taxi. In addition, a lot of access points existing along this road which makes all vehicles concentrate at the first and second lane. 


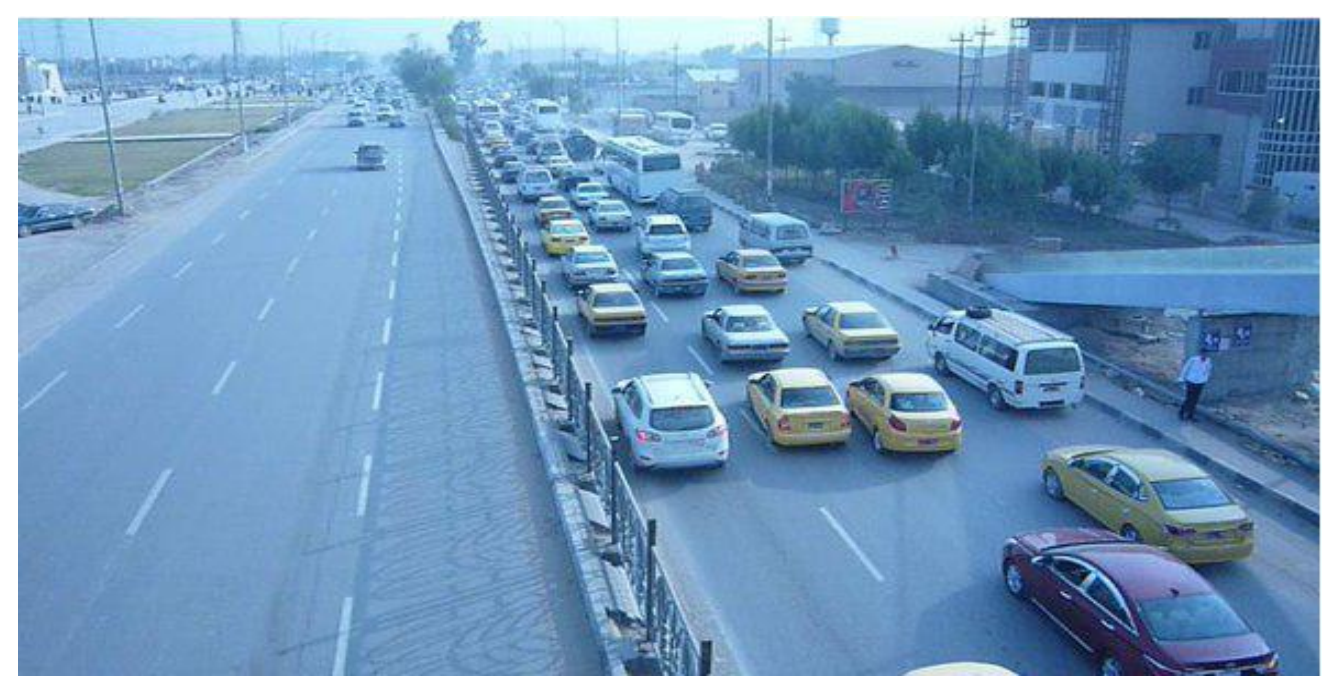

Fig. (8): Flow variation among lane toward kufa.

Figure 9 shows also the distribution of vehicles among the lanes. However, there is another queuing vehicle appear during the congested period forming the fourth lane as in
Figure 10. This behavior indicates unusual behavior and the absence of pavement marking has direct effect for such phenomena.

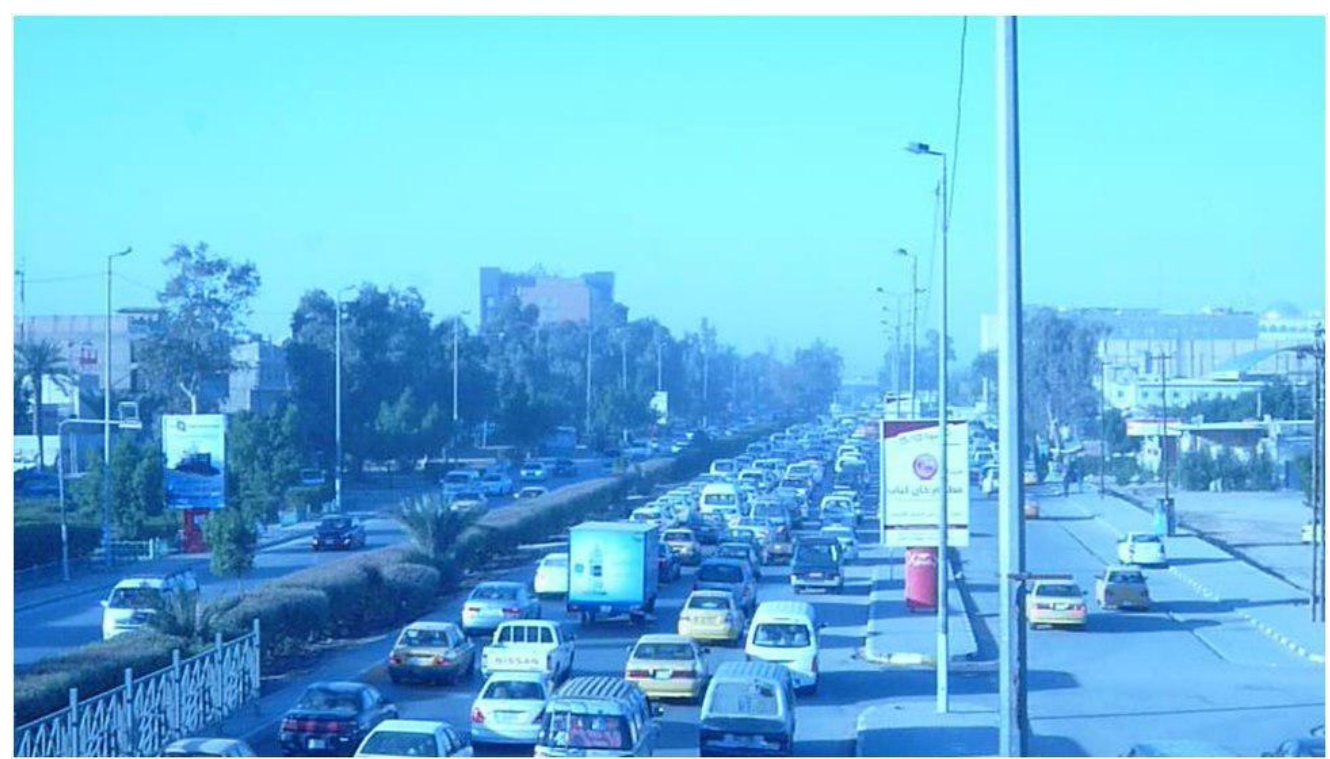

Fig. (9): Congestion at morning peak period in Kufa-Najaf road.

Finally, the analysis of LC with flow indicates that the number of LC is so high comparing with other countries as indicated in Figure 12 and 13. The highest number is up to $2000 \mathrm{LC} / \mathrm{hr} / \mathrm{km}$. This high number represents unstable drivers in the road and this also could be due to absence of pavement markings. Furthermore, on-street parking, by mini-bus was observed along the investigated sections in this study, may effect on increasing the number of LC.

hamid.aljameel@uokufa.edu.iq; alijkr1993@gmail.com 


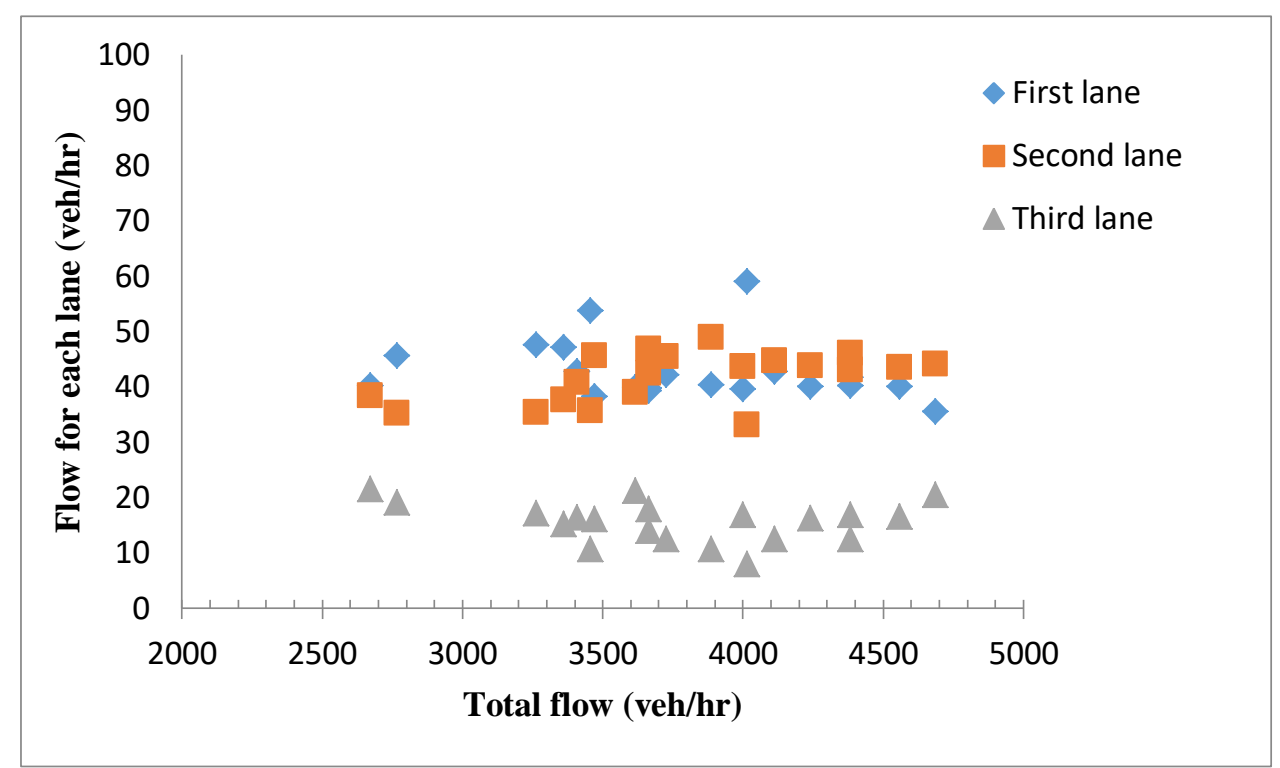

Fig. (10): LU of vehicles on each lane (toward Kufa).

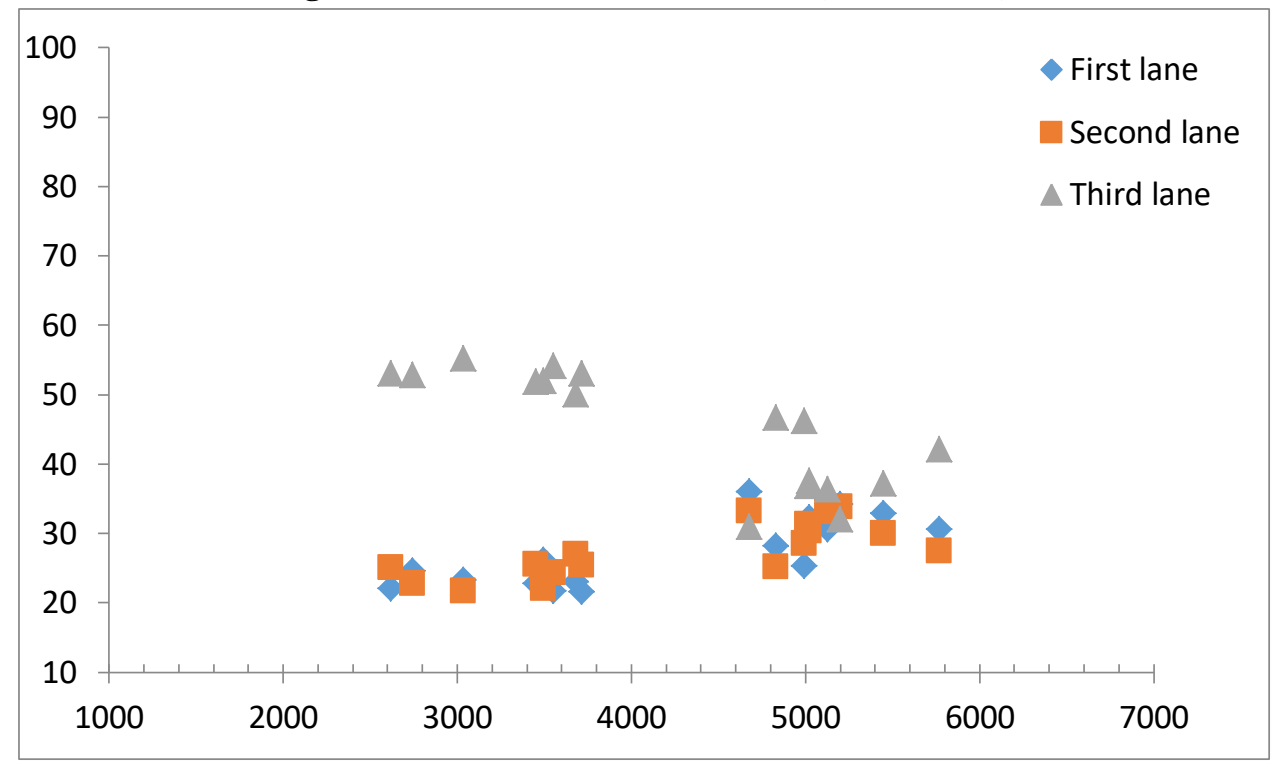

Fig. (6): Distribution of vehicles on each lane (to Najaf).

The high frequency of LC could be interpreted by high frequency of LC during moderate to high flow results in reducing speed and flow in the traffic stream. Kufa-Najaf road is from the major arterial urban in Al-Najaf city. This urban road is from the busiest one due to high traffic flow up to $9000 \mathrm{veh} / \mathrm{hr}$ in both directions during morning peak hour according to field data collection survey. Field data also indicated that driver behaviors are characterized by high number of LC which exceeds as mentioned in other countries as indicated in Figures 12 and 13. Specifically, the number of hamid.aljameel@uokufa.edu.iq;
LC has exceeded $2000 \mathrm{LC} / \mathrm{hr} / \mathrm{km}$ as indicated in Figure 12. Furthermore, the characteristics of LU indicates that the concentration of vehicles in the fastest lanes (i.e. second and third lanes) as indicated in Figures 10 and 11 with low percentage in the low lane (first lane). These behaviors have a significant effect on reducing the capacity comparing with normal behaviors as reported by other studies in different countries such as the UK, Germany and Turkey. The main causes determined by this study absence of suitable pavement markings which lead to unstable lane utilization and lane changing.

$$
\text { alijkr1993@gmail.com }
$$




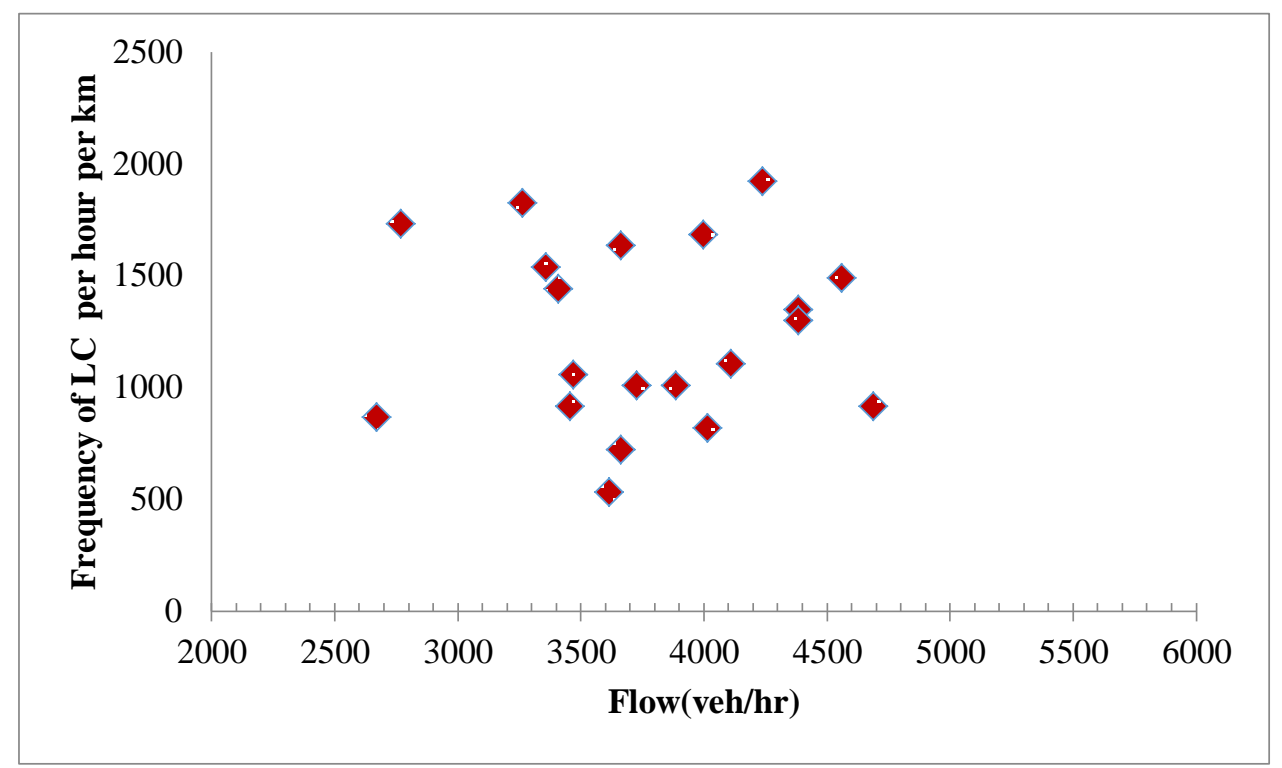

Fig. (7): FLC with flow within three lanes (toward Kufa).

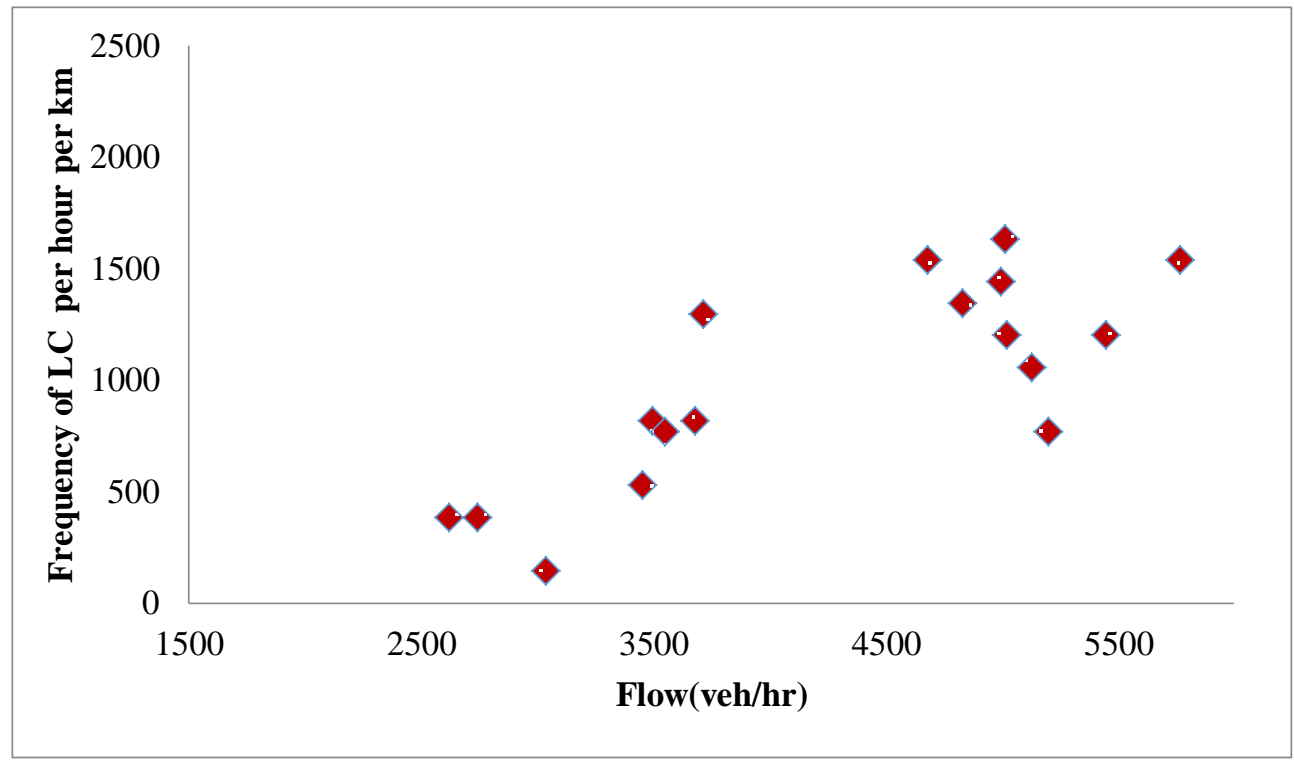

Fig. (8): FLC with flow within three lanes (toward Najaf).

\section{CONCLUSIONS}

The main important points of this study could be summarized as:

1- The high frequency of LC on Kufa-Najaf road is so high in compar with other countries. This may be attributed to driver behavior, the absence of pavement markings and the absence of pavement markings.

2- Lane utilization shows that most drivers concentrate on the second and third lanes hamid.aljameel@uokufa.edu.iq; whereas the first lane is the less one to carry traffic movement.

3- The Iraqi driver behavior of urban roads in terms of LU and LC is similar to the behavior in rural roads.

4- The main improvement of reducing LC could be implemented by preventing LC from right hand and providing suitable pavement markings.

\section{REFERENCES}

Al-Jameel, H. A. E. (2011). Developing a simulation alijkr1993@gmail.com

${ }^{1}$ Corresponding author: Faculty of Engineering, University of Kufa, Najaf, Iraq 
model to evaluate the capacity of weaving sections (Doctoral dissertation, University of Salford).

Al-Jameel, H. A., \& Kadhim, A. J. (2018). Some traffic characteristics of rural roads in Iraq. In MATEC Web of Conferences (Vol. 162, p. 01030). EDP Sciences.

Aydın, M. M., and Topal, A. (2018). Effects of pavement surface deformations on lane-changing behaviours. In Proceedings of the Institution of Civil EngineersTransport (Vol. 171, No. 3, pp. 136-145). Thomas Telford Ltd.

Aydin, M. M., Yildirim, M. S., Karpuz, O., and Ghasemlou, K. (2014). Modeling of driver lane choice behavior with artificial neural networks (ANN) and linear regression (LR) analysis on deformed roads. Computer Science \& Engineering, 4(1), 47.

Beentjes, R. M. (2012). Performance of rush-hour lanes and pluslanes: A study to behavioral factors and design factors.

Chick, C. (1996). On-street parking-A guide to practice. London, UK.

Choudhury, C. F. (2007). Modeling driving decisions with latent plans (Doctoral dissertation, Massachusetts Institute of Technology).

De Winter, J. C. F., and Dodou, D. (2010). The Driver Behaviour Questionnaire as a predictor of accidents: A meta-analysis. Journal of safety research, 41(6), 463-470.

Do, Q. H., Tehrani, H., Mita, S., Egawa, M., Muto, K., and Yoneda, K. (2017). Human drivers based active-passive model for automated lane change. IEEE Intelligent Transportation Systems Magazine, 9(1), 42-56.

Ghaffari, A., Khodayari, A., Hosseinkhani, N., and Salehinia, S. (2015). The effect of a lane changes on a car-following manoeuvre: anticipation and relaxation behaviour. Proceedings of the Institution of Mechanical Engineers, Part D: Journal of Automobile Engineering, 229(7), 809-818.

Gunay, B. (2004). An investigation of lane utilisation hamid.aljameel@uokufa.edu.iq; on Turkish highways. In Proceedings of the Institution of Civil Engineers-Transport (Vol. 157, No. 1, pp. 43-49). Thomas Telford Ltd.

Heidemann, D. (1994). Queue length and delay distributions at traffic signals. Transportation Research Part B: Methodological,28(5), 377-389.

Hidas, P. (2005). Modelling vehicle interactions in microscopic simulation of merging and weaving. Transportation Research Part $C$ : Emerging Technologies, 13(1), 37-62.

Hobbs, F. D. (1979). Traffic Planning and Engineering, Pergamon Press Oxword.

ITE, Institute of Transportation Engineers. (1992). Traffic Engineering Handbook. Fourth Edition. James, J.L eds. Prentice Hall New Jersey, pp.204-238.

Kimber, R. M. (1984). The effects of wheel clamping in Central London. TRRL Laboratory report, (1136).

Lawton, R., Parker, D., Manstead, A. S., and Stradling, S. G. (1997). The role of affect in predicting social behaviors: The case of road traffic violations. Journal of applied social psychology, 27(14), 1258-1276.

Lee, S. E., Olsen, E. C., and Wierwille, W. W. (2004). A comprehensive examination of naturalistic lane-changes (No. FHWA-JPO-04-092). United States. National Highway Traffic Safety Administration.

Lu, L., Ren, G., Wang, W., Chan, C. Y., and Wang, J. (2016). A cellular automaton simulation model for pedestrian and vehicle interaction behaviors at unsignalized mid-block crosswalks. Accident Analysis \& Prevention, 95, 425-437.

Moridpour, S., Sarvi, M., and Rose, G. (2010). Lane changing models: a critical review. Transportation letters, 2(3), 157-173.

Nassrullah, Z. F. A. (2016). Development of a micro-simulation model for motorway roadworks with the use of narrow lanes and lane closure schemes (Doctoral dissertation, University of Salford). alijkr1993@gmail.com

\footnotetext{
${ }^{1}$ Corresponding author: Faculty of Engineering, University of Kufa, Najaf, Iraq
} 
Nordfjærn, T., and Rundmo, T. (2009). Perceptions of traffic risk in an industrialised and a developing country. Transportation research part F: traffic psychology and behaviour, 12(1), 91-98.

Parker, D., West, R., Stradling, S., and Manstead, A. S. (1995). Behavioural characteristics and involvement in different types of traffic accident. Accident Analysis \& Prevention, 27(4), 571-581.

Peden, M. (2004). World report on road traffic injury prevention.

Pompigna, A., and Rupi, F. (2017). Lane-distribution models and related effects on the capacity for a three-lane freeway section: case study in Italy. Journal of Transportation Engineering, Part A: Systems, 143(10), 05017010.

Rahman, M., Chowdhury, M., Xie, Y., and He, Y. (2013). Review of microscopic lane-changing models and future research opportunities. IEEE transactions on intelligent transportation systems, 14(4), 1942-1956.

Ramanujam, V. (2007). Lane changing models for arterial traffic (Doctoral dissertation, Massachusetts Institute of Technology).

Reason, J., Manstead, A., Stradling, S., Baxter, J., and Campbell, K. (1990). Errors and violations on the roads: a real distinction? Ergonomics, 33(10-11), 1315-1332.

Shirke, C., Sumanth, N., Arkatkar, S., Bhaskar, A., and Joshi, G. (2019). Modeling expressway lane utilization and lane choice behaviour: a case study on Delhi-Gurgaon
Expressway. Transportation letters, 11(5), 250-263.

Sun, D. J., and Elefteriadou, L. (2011). Lane-changing behavior on urban streets: A focus group-based study. Applied ergonomics, 42(5), 682-691.

Toledo, T., and Zohar, D. (2007). Modeling duration of lane changes. Transportation Research Record, 1999(1), 71-78.

Transport and Road Research Laboratory, TRRL Laboratory Report 1136, Crowthorne.

Turner, D. (1999). Red Routes and Parking. Parking News, (174).

World Health Organisation, 2013; World Health OrganisationGlobal Status Report on Road Safety.

Xu, G., Liu, L., Ou, Y., and Song, Z. (2012). Dynamic modeling of driver control strategy of lane-change behavior and trajectory planning for collision prediction. IEEE Transactions on Intelligent Transportation Systems, 13(3), 1138-1155.

Yousif, S. Y. (1993). Effect of lane changing on traffic operation for dual carriageway roads with roadworks (Doctoral dissertation, University of Wales. Cardiff).

Yousif, S., Al-Obaedi, J., and Henson, R. (2013). Drivers' lane utilization for United Kingdom motorways. Journal of transportation engineering, 139(5), 441-447.

Yousif, S., and Hunt, J. (1995). Modelling lane utilisation on British dual-carriageway roads: effects on lane-changing. Traffic engineering \& control, 36(12), 680-687. 